pesquisa em administração

\section{0 ensino de metodologia de pesquisa em administração}

Carlos Osmar Bertero
Da EAESP/FGV, do Imes/SP

O problema da pesquisa em administração entre nós, professores e estudantes de pós-graduaçáo, tem as características de um problema perene. As questóes metodológicas sáo postas e recolocadas, as pesquisas resultantes acabam sendo, aos nossos próprios olhos, em quantidade insuficiente e de qualidade insatisfatória. Se todos concordamos que tal situaçaro existe, ela manifesta prablemas de nossa área de conhecimento que deveráo ser peculiares. E inteligivel que eles aflorem num curso de metodologia da pesquisa em administraç̧o, que por isso mesmo se transforma num dos cursos problemáticos de um programa de pós-graduaçá em administraçáo. Como o resultado dos cursos acaba sendo freqüentemente insatisfatório, para docentes e alunos, podemos estar presos num ardil de causaçấo circular. A única maneira de rompê-lo talvez seja a reflexáo sobre alguns aspectos da questáo que nos propomos realizar ao longo deste trabalho.

O ensino de metodologia de pesquisa em administraçáo envolve aspectos interdisciplinares. $O$ que se tornou hábito chamar entre nós de metodologia da pesquisa envolve coisas táo diversas como a parte instrumental para á efetiva realizaçáo de uma pesquisa, aspectos epistemológicos concernentes à natureza, origem, limitaçoes e condicionamentos sócio-culturais do conhecimento questóes próprias de filosofia da ciência e até questóes de filosofia geral. $O$ fato de que tais questóes ño sejam explicitadas deve ser visto como indicaçato de pobreza analítica de nossa área e que conduz a que enfrentemos problemas sem a capacidade de identificálos, equacionálos e possivelmente encaminhar soluçoes.

Os instrumentos disponíveis para a realizaçá de pesquisa em administraçæo stáo muito grandes. Isto resul. ta em parte do desenvolvimento do próprio instrumental metodológico, pelo que os administradores ño sto responsáveis, e também pelo caráter eclético $d a$ administraçăo enquanto área de conhecimento. Seja para a realizaç̃o de pesquisas de campo, experimentos e semi-experimentos, a quantidade e a complexidade dos instrumentos disponiveis (entrevistas abertas ou fechadas, estruturadas ou não, questionários, escalas de mediçđo etc.) tornam o seu domínio suficientemente problemático para qualquer pesquisador. Não se deve, portanto, esperar que um professor de metodologia de pesquisa os domine por inteiro. $O$ que acaba aumentando o potencial de insatisfaçáo dos alunos com relaçào ao curso é que muitos esperam obter conhecimentos práticos de como lidar com estes instrumentos.

Além das técnicas para pesquisa de campo ou para a elaboraço de experimentos e semi-experimentos, há os instrumentos que se utilizam em pesquisa que ná seja de campo. Análise de dados secundários e análise de conteúdo (content analysis) constituem outros setores dotados de enorme complexidade e que contêm problemas que thes sto peculiares.

Os problemas epistemológicos e ligados à filosofia da ciência sáo particularmente importantes para que deixem de ser tratados num curso de metodologia da pesquisa. Se não por outra raž́o, pelo simples fato de que as questóes sto indispensáveis e náo há espaco em outras disciplinas que compoem o currículo de mestrado onde possam ser levantados. Se se espera que os cursos de pósgraduagáo (stricto senso) conduzam à formaçáo de pesquisadores e professores, é inevitável que se busque desenvolver consciência com relação ao conhecimento científico e suas singularidades quando comparado com outros tipos de conhecimento.

Além do que foi exposto, a pesquisa científica não pode ser vista como algo a ser realizado mediante a utilizaçáo de vários instrumentos para coleta de informaçós e análise. $O$ instrumentos metodológicos e 0 próprio design da pesquisa ñó sáo dotados de uma instrumentalidade pura ou neutra, mas refletem inevitavelmente posiģoes epistemológicas e, por vezes, até metafísicas. Quando o design da pesquisa implica formular hipoteses e posterior operacionalizaçáo com a elaboraça de questionários que coletem as informacoes que operacionalizam as variáveis e sirvam, portanto, à sua comprovaçato empírica, estaremos operando com base em grande número de pressupostos epistemológicos. Ou, noutros termos, já respondemos a várias questóes sobre a natureza do conhecimento científico, sobre suas possibilidades e sobre os processos de obter conhecimentos. Um design de pesquisa como o proposto no exemplo subscreveria uma concepsáo que passaria pelo positivismo e, consequientemente, reafirmaria o empirismo como fonte de conhecimento.

Em outro exemplo hipotético, poderfamos imaginar um design de pesquisa onde o pesquisador elaborasse algumas hipóteses, nđo empiricamente derivadas, mas que se colocassem ao longo do modelo lancado por Max Weber em seu "tipo ideal", e que táo freqüentemente se tem colocado em pesquisa social. Talvez até com mais freqüôncia do que muitos pesquisadores gostariam de reconhecer. Mesmo que em tal tipo de pesquisa se partisse 
para comprovar empiricamente o "tipo ideal", já nos ter íamos distanciado do positivismo e do empirismo de nosso exemplo anterior. $O$ "tipo ideal" náo pode ser compreendido fora de uma posiçáo epistemológico idealista, e mais ainda, vinculada de alguma forma ao neokantismo. Se tomarmos um livro de moda e popularidade, na verdade, um best-seller, como Teoria $Z$ de William Ouchi, năo poderemos entender seus três tipos organizacionais (tipo $A$, tipo $J$ e tipo $Z$ ) como elaboraçóes teóricas no sentido positivista, mas como "tipos ideais" ao estilo weberiano. Se o autor utiliza os tipos organizacionais ideais propostos como base para prescriçбes ou recomendações para a ação administrativa, encontramo-nos já diante de outra dimensáo de grande complexidade que é a da aplicação do conhecimento. A questáo da aplicação levanta outros problemas clássicos de epistemologia como o da utilizaçáo e da própria fínalidade do conhecimento.

Um curso de metodologia de pesquisa, a despeito de seu título, náo pode ser um curso voltado exclusivamente aos aspectos instrumentais, sendo portanto um apanhado dos instrumentos e técnicas de pesquisa de uso possível na pesquisa administrativa. É necessário que se abordem problemas epistemológicos e de filosofía da ciência. Isto porque a instrumentaçáo da pesquisa é sempre caudatária de certas posiçőes epistemológicas e carrega pressupostos que sáo até mesmo metafísicos. $O$ fato de não tratá-los explicitamente e de náo assumi-los em nada afeta sua existência e sua influência. Portanto, parece-nos mais razoável assumir a problemática epistemológica subjacente aos problemas de metodologia de pesquisa e depois passar a possíveis aceitaçóes e rejeiçóes de métodos, designs e tipos de pesquisa administrativa. 0 próprio exercício da crítica, inseparável da atitude científica que se pretende desenvolver entre mestrandos e doutorandos, não pode ter base suficientemente sólida sem o tratamento da problemática epistemológica.

Os alunos que chegam a um curso de pós-graduaçáo normalmente têm pequena ou nenhuma familiaridade com a área de metodologia de pesquisa; mesmo que tenham cursado alguma coisa a respeito a nível de graduaçăo, verifica-se ao entrar na pós-graduaçáo uma mudança radical. $O$ aluno de graduação adotaria, com relaçáo a metodologia da pesquisa, uma atitude de conhecer mais uma matéria, sempre meio como espectador. $O$ pósgraduando adota com relaçao ao curso a atitude de usuário condicionada pela pressáo de ter que redigir uma tese para obtenção do grau. Conseqüentemente, sua atitude deixa de ser a de um espectador para ser a de um solicitador de instrumentos de trabalho. $O$ pós-graduando percebe-se, e o clima de um curso de pós-graduaçáo aguça esta percepção, como alguém que deverá produzir algo que incorpore 0 instrumental metodológico.

Náo é raro que às vezes se utilize um curso de metodologia de pesquisa como o local para se tentar elaborar o projeto de tese. Tal concepçáo de um curso de metodologia seria a conseqüệncia extrema de uma visão puramente instrumental. Em que pese às expectativas dos alunos $e$ as tensóes $e$ ansiedades para que se elabore o "mais cedo possivel" um projeto de tese, acreditamos equivocada a utilizaçá de um curso de metodologia de pesquisa para que tal projeto seja realizado.
Os alunos terão a ganhar com a redução do caráter instrumental do curso, sem todavia atingir a sua eliminação, e pela introdução de uma dimensão reflexiva e portanto filosófica e epistemológica.

Os problemas específicos da instrumentalidade, onde caberia perfeitamente a elaboração de um projeto de pesquisa ligado à tese, deveriam ser tratados num outro curso, de preferência vinculado à área de concentração do aluno. Esta separaçáo em dois cursos, lecionados por professores diferentes, parece atender melhor às peculiaridades da pesquisa em administraçáo.

A dificuldade da consolidaçato científica em administração não exclui um grande ecletismo. Aliás, epistemologicamente, cabe a pergunta se a administração existe como área específica de conhecimento. Isto leva a que se indague se pesquisas que são consideradas administrativas não estão tratando com outras áreas de conhecimento como a economia, a sociologia, a psicologia, a estatística, a matemática aplicada etc.. Sob esta perspectiva, talvez ficasse realmente difícil ver em muita pesquisa administrativa clássica, ou seja, aceita, conhecida e amplamente circulada entre estudiosos de administração, conteúdo propriamente administrativo.

Tomem o exemplo da pesquisa de Mayo e seus associados realizada na fábrica de Hawthorne da Western Eletric. Acredito que ninguém levantaria dúvidas sobre o fato de que o trabalho é sémpre visto como peça clássica da literatura e da pesquisa administrativa. Ora, até que ponto o que lá está investigado não pode ser visto como um trabalho envolvendo pequeno grupo, relaçoes intragrupais, estilos de liderança, motivaço no trabalho, - lugar da fábrica no universo psicológico da operária etc., e, portanto típico da psicologia, e mais especificamente da psicologia social? Se aceitamos que o trabalho de Hawthorne implica montagem que envolve um experimento, enquanto design de pesquisa, poderemos até vê-lo como uma pesquisa que no seu tempo foi de vanguarda em termos metodológicos. Porém, nada disso permite reclamar de maneira inconteste o seu caráter de pesquisa administrativa. A comunidade dos psicólogos sociais e organizacionais tende a ver Hawthorne como marco importante no desenvolvimento de vários tópicos da psicologia.

Poderíamos tomar outros trabalhos como exemplo e verificar que sociólogos, economistas, cientistas políticos, náo os consideram especificamente administrativos, mas localizados em suas áreas específicas de coṇhecimento. Tal tipo de discussio é particularmente inquietante, porque expoe nossa fragilidade científica e nossa capacidade em delimitar epistemologicamente um dominio. Sem aprofundar aqui a discussáo, o que foi levantado é suficientemente para expor o caráter eclético da administração e a diversidade de teorias e metodologias que podem ser utilizadas nas várias subáreas da administração. Embora coisas como finanças, marketing, organizaçóes e operaçóes constem de um mesmo programa como "simples" áreas de concentraçáo, não há como negar a grande diversidade de métodos e de teorias e sistemas que dificultam a colocaço de todas estas pessoas num único curso de metodologia de pesquisa. Os interesses de cada área serão melhor atendidos se os cursos de projetos de pesquisa forem ministrados sob a responsabilidade de 
professores das áreas respectivas. Isto porque, enquanto um estudioso da área de marketing prepara um projeto empírico que utiliza instrumentos de pesquisa de campo nitidamente vinculados a uma visto empirista de construçáo de teorias e com pesadas tinturas de positivismo lógico, manejando hipóteses baseadas em teorias da motivação que são do domínio específico da psicologia, outro estudioso, da área de operaçбes, está trabalhando no desenvolvimento de um algoritmo, que utiliza teorias matemáticas e estatísticas e depende de um modelo de construção de teorias que se vincula a uma posição idealista e que prescinde inteiramente da experiência empírica, tanto na fase de elaboraçáo teórica, como pela eliminação de qualquer comprovaçáo empírica.

As peculiaridades apontadas das várias áreas de concentração que constituem a administraçăo, bem como a grande dificuldade em delimitar epistemologicamente uma área específica de conhecimento, recomendam que se separe a reflexão epistemológica e a instrumentalização de pesquisa em duas etapas, correspondendo a dois cursos distintos. Acrescente-se ainda que o curso instrumental deve, sempre que possível, ficar sob a responsabilidade da área de concentraçáo respectiva.

Até o momento abordamos os problemas dos alunos da pós-graduaçáo e as peculiaridades da administraçáo enquanto área de conhecimento. Agora seria interessante indagar sobre os problemas dos professores que habitualmente se ocupam do ensino de metodologia de pesquisa em cursos de pós-graduação em administraçáo. É comum que $o$ docente de metodologia de pesquisa tenha formaçấo em ciências sociais. Para ensinar em cursos de administraçáo, isto traz dois tipos de desvantagens ou limitaçбes. Primeiramente é sua pouca familiaridade com a área de administração em termos de conteúdo do próprio conhecimento administrativo. Em.segundo lugar há o desconhecimento de uma série de problemas metodológicos próprios das áreas de conhecimento administrativo que se distanciam das ciências sociais, ou seja, finanças, produção e operaçoes e métodos quantitativos aplicados à administraçáo. É possivel incluir aqui certas abordagens da área de marketing. As duas limitaçoes mencionadas sáo bastante graves e seria desejável que não existissem. Sua solução só ocorreria se os metođólogos com formaçāo em ciências sociais, se interessassem por administração ou se tivéssemos. professores com formação básica em administraçăo e que se interessassem por metodologia de pesquisa.

O desconhecimento do conteúdo da área de administração provoca inevitável distanciamento com relação aos alunos e pode encaminhar o curso para um tipo de exercício um pouco abstrato e distanciado. Isto resulta num curso mis formal to que se desejaria. 0 problema é de solução difícil e talvez o mais razoável fosse desenvolver interesse e competência em metodologia em professores de administração, já que é menos provável que cientistas sociais ou mesmo pessoas com formaço em filosofia e epistemologia venham a se interessar em familiarizar-se com conhecimentos administrativos.

Outro problema com relaçá a um docente de metodologia de pesquisa com formaçăo em ciências sociais é a sua menor competência com o tratamento quantitativo, o que inclui náo só a análise e os modelos matemáti- cos em suas aplicaçóes administrativas, mas o conhecimento de análise estatística. Isto é devido a uma lamentável, mas real dicotomia em nossa escolarização brasileira, que separa o quantitativo do qualitativo desde a precoce e indevida bifurcação entre exatas e humanas. $\mathbf{E}$ neste tipo de divisáo as ciências sociais sto alinhadas com as humanas, o que resulta sempre em precária formação quantitativa desde a escola secundária e que prossegue na universidade. Embora cursos de graduação de ciências sociais e de psicologia incluam em seus currículos mínimos análise estatística, é conhecida a deficiência de tais cursos e o papel marginal com que sáo vistos pelos próprios docentes e alunos dos respectivos cursos. Como decorrência de tal situação, o metodólogo que tenha formação básica em ciéncias sociais năo logrou compensar suas lacunas de estatística e analises quantitativas. Isto, associado a uma rejeiçâo mais preconceituosa do que propriamente crítica, do tratamento estatístico dos dados de pesquisa de campo, acabam por explicar a fraqueza de nossas pesquisas em cièncias sociais em termos metodológicos. Lastimavelmente, associa-se o tratamento estatístico e quantitativo com funcionalismo estrutural e positivismo lógico. A rejeiçáo de tais posiçós em teoria e epistemologia justificariam descartar a estatística e o esforço da busca do rigor. Para os que adotam tais posturas, freqüentemente escudadas em alguma forma de marxismo, conviria lembrar que em nenhum momento e em nenhum ponto o marxismo enquanto filosofia e concepça do processo do conhecimento justificou qualquer afastamento da realidade empírica e deixou de recomen. dar o seu tratamento rigoroso.

O que importa é que a deficiência no manejo de técnicas quantitativas, freqüentemente acompanhada de uma atitude preconceituosa contra elas, nao leva a que tal competência seja buscada em cursos de metodologia de pesquisa em administraçáo. Como é razoável, atualmente, a importância do tratamento quantitativo em boa parte da pesquisa em administraçáo (realizada, evidentemente, fora do Brasii), continuamos a permanecer à margem tálvez da pesquisa de vanguarda que se realiza.

Há uma forma bastante disseminada entre nós de ver cursos de metodologia de pesquisa como propedéuticos. Conseqüentemente, sáo colocadas na parte inicial dos programas, antes mesmo de se entrar em matérias substantivas do núcleo obrigatório ou das várias áreas de concentraça. Este posicionamen to do curso de metodologia de pesquisa está aberto ao questionamento. Se o seu caráter fosse puramente instrumental, tal posiçăo seria menos vulnerável; porém, se o objetivo do curso, sem excluir a instrumentação da pesquisa, envolver também a reflexáo epistemológica, entáo o posicionamen to é claramente equivocado. Se no início do curso os alunos, em princípio, ainda náo tiverem acesso ao conteúdo da área administrativa, como se pode esperar que realizem tarefas de reflexáo? Poder-se-ia perguntar facilmente sobre o que refletir, já que ainda não lhes foi dada matéria para tanto. Deste ponto de vista, aplica-se à metodologia de pesquisa o mesmo tipo de reflexáo que classicamente se fazia a propósito do ensino e da reflexáo lógica. Se entendermos a lógica como disciplina que prepara e instrumenta a razto para a filosofia e para a ciência, a visto propedêutica ainda é, em princípia, sustentável. Porém, 
se entendermos a lógica como uma "reflexáo" da razáo sobre si mesma, suas formas, estrutura e procedimentos fundamentais, então não se justifica em absoluto o caráter propedêutico da lógica. Ela surge necessariamente como etapa reflexiva, ou seja, posterior a uma razão que já exerceu e que gerou e sistematizou algum conhecimento. Aliás, esta é a realidade histórica da própria lógica e o seu aparecimento náo precedeu a ciência e a filosofia. $\mathrm{Na}$ verdade o oposto aconteceu, pois quando a lógica se esboça e consolida, especialmente no pensamento platônico e aristotélico, já se havia filosofado razoavelmente na Grécia. Estas observações sobre a lógica podem ser estendidas ao problema do posicionamento e da própria natureza da metodologia de pesquisa. Atualmente, o que se faz em metodologia, ou o que se espera da metodologia, é em boa medida o que se esperava da lógica em outros tempos. Porém, deve-se atentar que as ciências sociais e a pesquisa administrativa ñáo precederam a sociologia, a psicologia, a economia ou a administraçato. Inversamente, obras clássicas e decisivas nas ciencias respectivas surgiram antes da "metodologia" com caráter propedêutico. Adam Smith, Comte, Marx, Durkheim produziram suas obras, ao que conste, sem grandes preocupaçes metodológicas e sem utilizarem designs previamente preparados. Foi apenas a partir das obras de cientistas como os citados que a metodologia se colocou em um caráter reflexivo.

Igualmente, náo se pode pretender que o ensino de metodologia de pesquisa seja entendido como sendo propedêutico à realizaçáo da pesquisa. A disciplina revestese de caráter reflexivo e esta reflexáo deverá exercer-se sobre um conhecimento existente e já apropriado pelos alunos. Isto conduz à questáo de qual a amplitude de conhecimentos administrativos dominados por alunos de pós-graduaçáo e, mais especialmente, em suas áreas de concentraçato respectivas.

\section{ONDE OUER OUE VOCÊ ESTEJA CHEGAMOS ATÉ VOCE}

\section{LIVROS E PERIÓDICOS OA FGV PELO REEMBOL $O$ POATL}

\section{Pedidos à.}

Fundaçăo Gatulio Vargas/Editora

Divișia de Vendas

Caixa Postal 9052

20000 - Rio de Janeiro - R
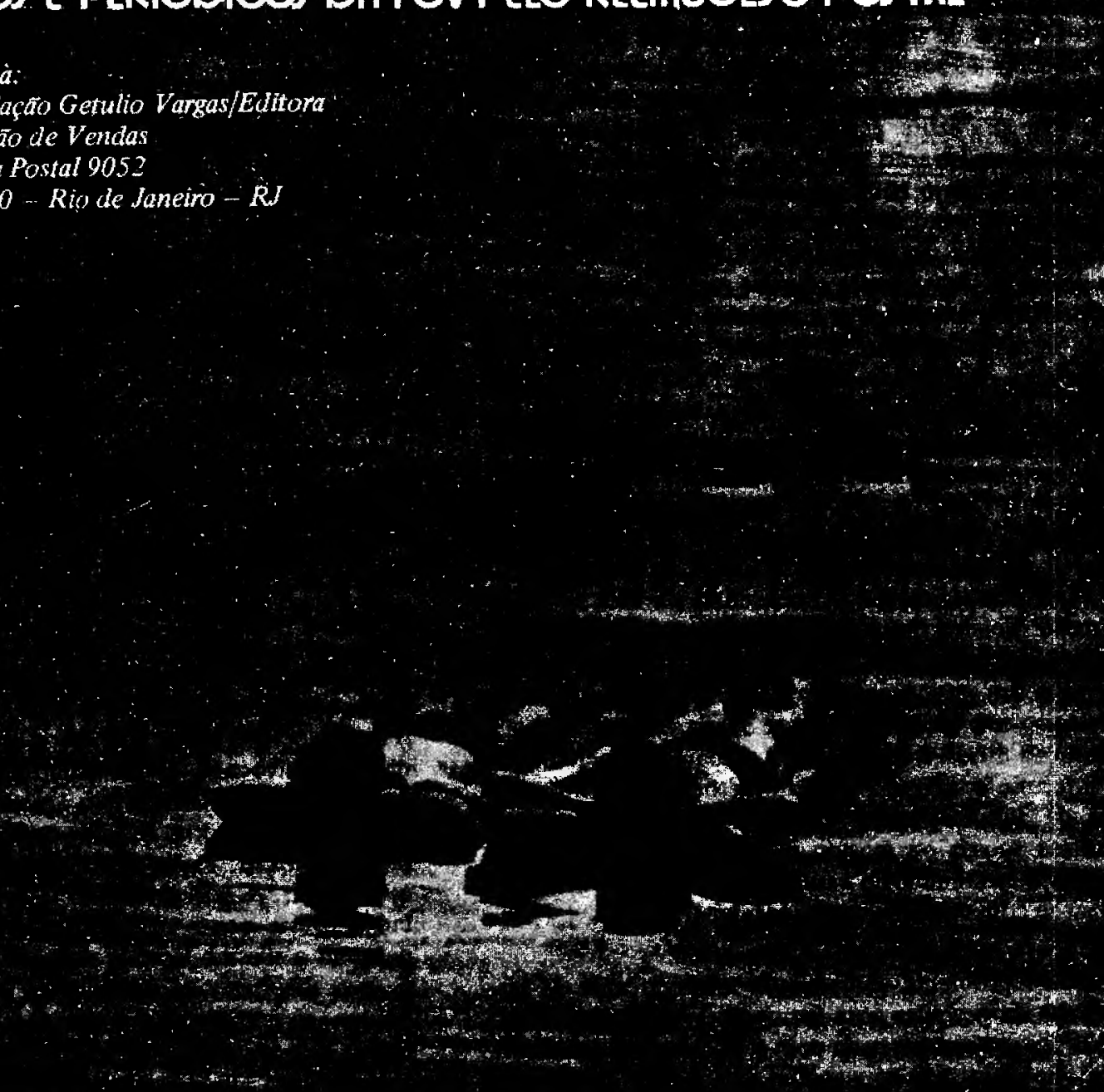

ifte
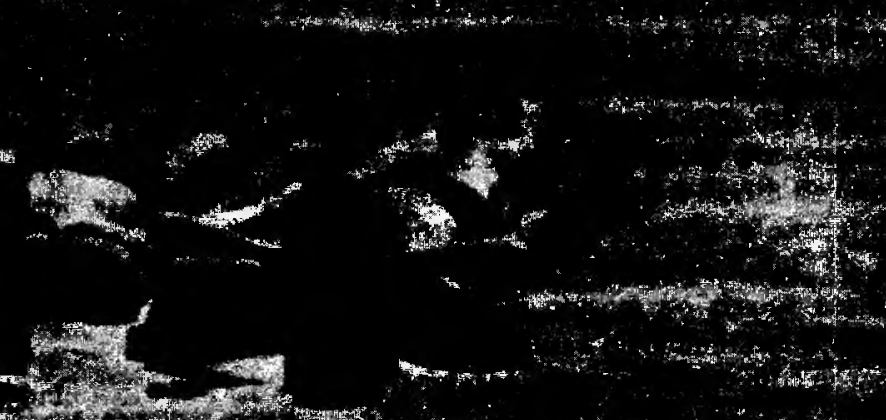

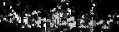
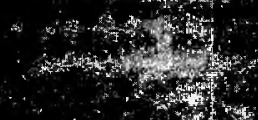

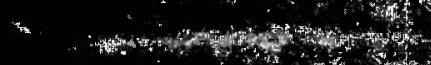
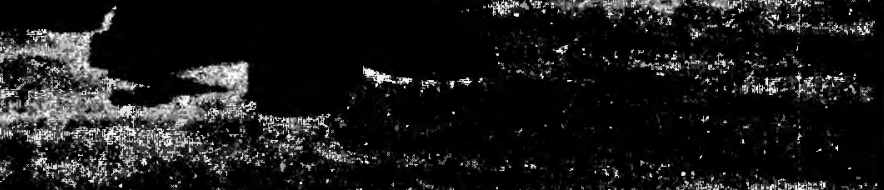